\title{
CÓMO ESCRIBIR UNA REVISIÓN POR PARES: 12 COSAS QUE DEBES SABER
}

\section{How to Write a Peer Review: 12 things you need to know}

\author{
Jo WILKINSON¹; Beatriz PARDAL-PELÁEZ² \\ ${ }^{1}$ Publons. Jefe de Comunicaciones. \\ ${ }^{2}$ Universidad de Salamanca. Departamento de Cirugía. Salamanca. España \\ Correspondencia: jo@publons.com
}

Fecha de recepción: 3 de enero de 2018

Fecha de aceptación: 23 de enero de 2018

Fecha de publicación: 24 de enero de 2018

Fecha de publicación del fascículo: 1 de diciembre de 2018

Conflicto de intereses: Los autores declaran no tener conflictos de intereses

Imágenes: Los autores declaran haber obtenido las imágenes con el permiso de los pacientes

Política de derechos y autoarchivo: se permite el autoarchivo de la versión post-print (SHERPA/RoMEO)

Licencia CC BY-NC-ND. Licencia Creative Commons Atribución-NoComercial-SinDerivar 4.0 Internacional

Universidad de Salamanca. Su comercialización está sujeta al permiso del editor

RESUMEN

\begin{abstract}
Introducción y objetivo: La revisión por pares no solo ayuda a mantener la calidad e integridad de la literatura en tu campo, es la clave de tu propio desarrollo como investigador. Es una excelente manera para mantenerse al tanto de la investigación actual, impresionar a los editores en revistas de élite y perfeccionar tus habilidades de análisis crítico. Recopilamos 12 pasos para revisar un artículo. Método: Le preguntamos a un panel de expertos de investigadores qué pasos toman para garantizar una revisión exhaustiva y sólida. Luego recopilamos sus consejos en 12 sencillos pasos, útiles tanto para quienes revisan por primera vez como para quienes desean mejorar sus habilidades. Conclusiones: Vale la pena tener en cuenta que cada uno de estos 12 pasos merece una publicación por derecho propio. Si deseas obtener una idea más completa de la revisión por pares y hacer uso de nuestra propia plantilla de revisores, regístrate en Publons Academy. Este curso gratuito te enseña las competencias básicas de la revisión por pares y te conecta con editores de revistas para que puedas poner en práctica tus habilidades.
\end{abstract}

PALABRAS CLAVE revisión por pares; Publons Academy

SUMMARY

$$
\begin{aligned}
& \text { Peer review not only helps to maintain The quality and integrity of literature in your field, it's } \\
& \text { key to your own development as a researcher. It's a great way to keep abreast of current re- } \\
& \text { search, impress editors at elite journals, and hone your critical analysis skills. We collect } 12 \\
& \text { steps to review an article. Method: We asked an expert panel of researchers what steps they } \\
& \text { take to ensure a thorough and robust review. We then compiled their advice into } 12 \text { easy steps, } \\
& \text { useful for both first-time peer reviewers and those keen to brush up on their skills. Conclusions: } \\
& \text { It's worth bearing in mind that each of these } 12 \text { steps deserves a publication in its own right. If } \\
& \text { you'd like a more complete picture of peer review and to make use of our very own Review } \\
& \text { Template, sign up for our Publons Academy. This free on-demand course teaches you the core }
\end{aligned}
$$


competencies of peer reviewing and connects you with journal editors, so you can put your skills into practice.

\section{INTRODUCCIÓN}

Completar una revisión por pares no es poca cosa. Como revisor eres responsable de proteger al público de datos falsos y engañosos, y ayudar a descubrir avances fidedignos. Además, se te exige realizar una crítica constructiva del trabajo de tus compañeros, a algunos de los cuales les ha supuesto sangre, sudor, lágrimas y años ponerlos en orden.

Esto significa que, desafortunadamente, la revisión por pares es un poco más complicada que elegir entre un bolígrafo rojo y verde. Pero, a pesar de esto, la revisión por pares no tiene por qué ser difícil ni estresante, ni dejarte con una sensación de fracaso. En realidad, es un proceso muy estructurado que se puede aprender y mejorar cuanto más lo hagas, y serás más rápido y seguro a medida que pase el tiempo. Muy pronto empezarás incluso a beneficiarte del proceso.

La revisión por pares no solo ayuda a mantener la calidad e integridad de la literatura en tu campo, es la clave de tu propio desarrollo como investigador. Es una excelente manera para mantenerse al tanto de la investigación actual, impresionar a los editores en revistas de élite y perfeccionar tus habilidades de análisis crítico. Te enseña a revisar un manuscrito, detectar errores comunes en documentos de investigación y mejorar tus posibilidades de ser un autor con éxito [1, 2].

Para sacar el máximo provecho del proceso de revisión por pares, debes tener en mente los mejores consejos y técnicas desde el principio. Aquí es donde entramos nosotros.

Le preguntamos a un panel de expertos de investigadores qué pasos toman para garantizar una revisión exhaustiva y sólida. Luego recopilamos sus consejos en 12 sencillos pasos, útiles tanto para quienes revisan por primera vez como para quienes desean mejorar sus habilidades.

Combinados, nuestros expertos cuentan con más de 577 evaluaciones por pares prepublicación para 101 revistas diferentes y son miembros de siete paneles editoriales. Incluyen a: Ana Marie Florea, investigadora principal y científica principal del Instituto de Neuropatología, Heinrich-Heine de la Universidad de Düsseldorf; James Cotter, fisiólogo de ejercicio y medio ambiente y profesor asociado de la Universidad de Otago en la Escuela de Educación Física; y Robert Faff, profesor de finanzas y director de investigación de la Universidad de Queensland.

Vale la pena tener en cuenta que cada uno de estos 12 pasos merece una publicación por derecho propio en el blog (busca los enlaces -https://publons.com/blog/-). Si deseas obtener una idea más completa de la revisión por pares y hacer uso de nuestra propia plantilla de revisores, regístrate en Publons Academy. Este curso gratuito te enseña las competencias básicas de la revisión por pares y te conecta con editores de revistas para que puedas poner en práctica tus habilidades.

\section{PASOS PARA ESCRIBIR UNA REVISIÓN}

1. Asegúrate de que tienes la habilidad adecuada (lee nuestra publicación "Are you the right reviewer? 5 questions to ask yourself») [3].

2. Ve a la página web de la revista para aprender las instrucciones específicas para revisores. Comprueba que el manuscrito se adapta al formato de la revista y que las referencias están estandarizadas (si el editor no lo ha hecho ya).

3. Échale un vistazo rápido al trabajo para tener una idea general. Subraya las palabras clave y argumentos, y resume los puntos clave. Esto te ayudara a sintonizar rápidamente con el trabajo en la próxima lectura.

4. Siéntate en un lugar tranquilo y lee el manuscrito críticamente (lee nuestros 12 mejores consejos) [1]. Asegúrate de que tienes las tablas, figuras y referencias visibles. Hazte preguntas clave, incluyendo: ¿Tiene un título relevante y una pregunta de investigación valiosa?, ¿están citados los trabajos clave?, ¿cuál es la motivación del autor para realizar el estudio y la idea detrás del mismo?, ¿son los datos y las herramientas adecuados y correctos?, ¿qué hay de nuevo en esto?, ¿por qué es importante?, ¿existen otras consideraciones?

5. Toma notas de las revisiones mayores, moderadas y menores que hay que realizar. 
6. Crea una lista de cosas que hay que comprobar. Por ejemplo, ¿los estudios de referencia muestran realmente lo que se afirma en el documento?

7. Evalúa el lenguaje y la gramática, y asegúrate de que se adapta correctamente a la revista. ¿Fluye el trabajo y tiene conectividad?, ¿tiene claridad y las palabras y la estructura son concisas y efectivas?

8. Verifica las publicaciones previas de los autores y de otros autores en el campo para asegurarte de que los resultados no han sido publicados previamente.

9. Confirma que no hay errores comunes (lee «6 Common Flaws To Look Out For in Peer Review» para ver errores de investigación comunes que se deben tener en cuenta) [2].

10. Resume tus notas para el editor (visión general, contribución, fortalezas y debilidades, aceptabilidad). Puedes incluir también la contribución y contexto del manuscrito para los autores (para aclarar si tú lo ves de forma similar o no), después prioriza y coteja las revisiones mayores y menores y específicas en comentarios. Intenta compilar esto de forma lógica, agrupando los elementos similares bajo un encabezado común si es posible, numerándolos para facilitar la referencia.

11. Proporciona recomendaciones específicas que los autores pueden hacer para la realización de cambios en los manuscritos. En total debes considerar una revisión de alrededor de dos o tres páginas (como máximo) de longitud.

12. Proporciona tu recomendación al editor.

Trabajo. Hecho.

Esperamos que estos 12 pasos te ayuden a avanzar en tu primera revisión por pares, o mejorar la estructura de tus revisiones actuales. Y recuerda, si quieres dominar las técnicas relacionadas con la revisión por pares y obtener acceso a nuestra plantilla de revisores, regístrate en Publons Academy.

\section{AGRADECIMIENTOS}

A Jo Wilkinson que amablemente ha accedido a publicar la versión traducida al castellano de la entrada de blog How to Write a Peer Review: 12 things you need to know [3] en Revista ORL.

\section{BIBLIOGRAFÍA}

1. Culley T. How to evaluate a manuscript critically: 12 questions you should always ask yourself.

En: https://publons.com/blog/how-tocritically-evaluate-a-manuscript-12questions-you-should-always-askyourself/. [Citado el 03/01/2018]

2. Wilkinson J. 6 Common Flaws To Look Out For in Peer Review.

En: $\quad$ https://publons.com/blog/6common-research-flaws-to-watch-outfor-in-peer-review/. [Citado el 03/01/2018]

3. Wilkinson J. How to Write a Peer Review: 12 things you need to know.

En: https://publons.com/blog/how-towrite-a-peer-review-12-things-youneed-to-know/. [Citado el 03/01/2018]

4. Culley T. Are you the right reviewer? 5 questions to ask yourself.

En: https://publons.com/blog/are-youthe-right-reviewer/. [Citado 03/01/2018]

\section{OTROS ENLACES DE INTERÉS}

- $\quad$ Ana Marie Florea

https://publons.com/author/242849/anamaria-florea\#profile

- James Cotter https://publons.com/author/440142/jam es-david-cotter\#profile

- Jo Wilkinson

https://publons.com/blog/author/jowilkinson/

- $\quad$ Publons Academy. Master of Peer Review https://publons.com/community/academ $\mathrm{y} /$

- $\quad$ Publons. Advance your career with Peer Review https://publons.com/community/career/

- Publons. Blog https://publons.com/blog/

- Robert Faff https://publons.com/author/480479/robe rt-faff\#profile 